\title{
As novas tecnologias de rádio na web e a desterritorialização da informação na construção do imaginário
}

\author{
GUSTAVO GUILHERME LOPES \\ Faculdade Internacional de Curitiba - gustavo@mt2.com.br
}

Pós-graduado em Comunicação e Informação, graduado em Comunicação Social pela Hélio Alonso (FACHA-RJ). Atualmente é diretor de planejamento da MT2 Editora e Publicidade Ltda., Coordenador do Curso de Comunicação Social e habilitações da Faculdade Internacional de Curitiba (FACINTER), Editor Chefe da Revista de Comunicação UNINTER.COM e Editor Chefe da Rádio Uninter Universitária e responsável pelo Jornal Marco Zero.

\section{Resumo}

O texto a seguir discute o uso das rádios na web como mediadoras da informação, dando acessibilidade desterritorializada através de dispositivos móveis e auxiliando na construção do imaginário contemporâneo promovido pelas novas tecnologias disponíveis a esta mídia, para entender como a recepção de novos conteúdos e novas possibilidades de interação com o ouvinte, mediada pelas novas tecnologias de emissão de informação, interferem na criação de um novo perfil de ouvinte.

Palavras-chave

Rádio, Desterritorialização, Tecnologia.

\begin{abstract}
The following text discusses the use of webradios as information mediators, giving deterritorialized accessibility through mobile devices and helping the construction of contemporary imagery promoted by new technologies available for this kind of media, understanding how the receipt of new contents and new possibilities of interaction with the listener, mediated by the new emission technologies of information, interfere in a creation of a new listener profile.
\end{abstract}

Keywords

Radio, Desterritorialization, Tecnology

Artigo recebido em 18/09/2010

Aprovado em 01/11/2010 


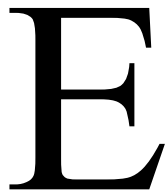

mpresas brasileiras vêm utilizando nos últimos anos, o rádio na web como ferramenta de suporte à informação. Esta tecnologia e interface, apesar de amplamente conhecidas, ainda estão em fase de adaptação tanto na parte técnica quanto na parte de planejamento e distribuição. A acessibilidade à interface e aos dispositivos para receber a informação, também são pontos fortes no potencial desta ferramenta, como difusora da informação e de sua desterritorialização propiciada pelos dispositivos capazes de receber a mensagem mediada.

A tecnologia de rádio via web é relativamente nova. $\mathrm{O}$ desenvolvimento desse tipo de protocolo de disseminação de informação é derivado de uma pesquisa feita pela Universidade de Columbia nos Estados Unidos, em meados dos anos 90, chamado de SIP, Session Initiation Protocol (Protocolo de Iniciação de Sessão)', visando formalizar um padrão de distribuição de conexões simultâneas para Internet.

O SIP foi o precursor das tecnologias atualmente disponíveis para a disseminação de qualquer distribuição de áudio e vídeo na internet. Hoje, as amplamente utilizadas são o streaming e o podcast $t^{i i}$. A tecnologia de streaming está presente em quase todos os processos de comunicação de áudio e vídeo utilizados na internet no momento.

O SIP identifica a melhor forma e protocolo a ser aberto para iniciar uma sessão de streaming ou podcast. Com a disponibilidade desta tecnologia, as empresas estão utilizando a radioweb, que faz uso do protocolo de streaming de voz, como uma ferramenta de apoio para a transmissão de informação e conhecimento.

\section{Mediando a informação}

Moran (2006), um dos especialistas no uso da internet como ferramenta auxiliar no processo comunicacional, considera que muitas empresas estão expandindo para o ambiente virtual, a exemplo do que se faz em todo o mundo, o que permite dar continuidade ao processo comunicacional fora da limitação locativa dos ambientes que possuam o aparato rádio. Essa modalidade na transmissão da informação passa a ser não só uma tendência, mas uma realidade com a aplicação da convergência da informação 
em diversas mídias propostas por Jenkins (2008), contribuindo assim para a desterritorialização e virtualização da informação conforme Levy (1996).

A cultura existente de recebimento de informação via áudio é através da linguagem de radiodifusão, segundo Bianco (1999), culturalizada e já enraizada em nosso cotidiano por sua presença no Brasil desde os anos 20. O meio rádio, ao longo destes quase 100 anos de história, desenvolveu uma linguagem própria de comunicação, sendo esta socialmente e conscientemente aceita por todos nós, ouvintes de rádio.

A linguagem tradicional de transmissão de informações pelo meio rádio convencional funciona muito bem para o meio locativo, onde temos um início e fim de alcance da emissão. Para a comunicação efetiva em uma rádio, agora mediada pela web, o tipo de comunicação deve ser revisto, pois o ouvinte não mais está interessado em informações locativas e sim nas possibilidades de interação com o meio, que pode lhe propiciar experiências desterritorializadas por intermédio de uma relação através dos dispositivos móveis de acesso a interface, embora o meio rádio, mesmo na web, continue impossibilitando a relação completa de nossos sentidos para com a informação transmitida.

A ausência de contato visual leva a uma série de alternativas sonoras para a codificação da mensagem. Resulta daí que a base para a recepção seja o sentido de audição como, em nível menor - por não ser o único elemento presente -, a fala é a base da transmissão. (FERRARETTO, 2000)

Existe uma potencialidade para a produção de conteúdo a ser transmitido por intermédio de rádios na web. Por outro lado, deve-se pensar na adequação do conteúdo transmitido pela mídia em questão, respeitando a linguagem do meio e a cultura existente na recepção e compreensão da informação transmitida.

Com a possibilidade de acesso às rádios veiculadas através da internet, a comunicação desterritorializada que já é uma tendência, torna-se muito mais atrativa para as empresas se consideradas as informações e possibilidades acima. A virtualização dos dados e a possibilidade de interação facilitam o processo de envio e recebimento da informação e atingem um público muito maior do que se compararmos com a atual estrutura comunicacional, que hoje conta basicamente com interações por intermédio de ligações telefônicas. Todos estes métodos dependem da corporificação real (HILLIS, 
1999) e locatividade do receptor em algum lugar específico e com alguma temporalidade previamente acordada (LEMOS, 2004). Ao mediar a informação via radioweb, não mais dependeremos das condições tempo e espaço para informar. Transpomos a primeira interface do rádio, que depende do aparelho em si, transpomos a interface moderna da figura do computador e monitor, que propiciava a recepção da radioweb via internet, mas dependia de cabos azuis, e partimos agora para a era dos dispositivos móveis onde conexões wireless possibilitam uma interface desterritorializada, tanto para o emissor quanto para o receptor. Nem um nem outro depende mais de locais, conexões ou extensões tecnológicas para propiciar ou mesmo respeitar as regras das teorias da comunicação entre emissão e recepção da mensagem.

Toda essa vantagem na mediação das rádios na web traz também uma grande preocupação no controle da informação disponibilizada. Existe um grande risco de o emissor perder completamente o controle do volume de receptores da informação mediada, e de não saber quem são eles. Não seria o caso de uma viralização da informação, pois a emissão via streaming é única e não pode ser modificada, mas sim a possibilidade de uma viralização na disseminação do endereço de acesso, códigos embed, de comentários em redes sociais e de replicações em outros endereços na web do link de acesso à informação, anteriormente exclusivo.

As três regras da cibercultura de Lemos (2002), Liberação do Pólo da Emissão, Conexão em Rede e Reconfiguração agem diretamente nesta questão. Transmitir áudio pela web, respeitando as regras acima caracteriza exemplarmente uma radioweb, mas gerenciar o conteúdo e a disseminação dessa informação na web pode ser trabalhoso. Essa possibilidade de perda de controle da informação mediada passa a ser uma preocupação para uns e vantajosa para outros, depende-se sempre do tipo de atuação e interação que se quer propiciar no ambiente da web.

\section{Novas interfaces para as rádios}

As tecnologias de comunicação estão se adaptando às novas interfaces para oferecer todos os serviços disponíveis online com versões para todos os dispositivos conectáveis a rede (JOHNSON, 2001), possibilitando ao usuário um acesso ilimitado e 
desterritorializado da informação. Cabe ao usuário, somente definir o que deseja receber de informação, aderindo ao que lhe interessa, utilizando os recursos disponíveis. Fugimos assim da recepção de uma mídia manipuladora, partindo para a construção do nosso próprio imaginário por intermédio de uma adesão voluntária das informações que achamos pertinentes (SILVA, 2003). O recebimento da informação perdeu seu caráter coletivista e agora somos os gatekeppers ${ }^{i i i}$ do que recebemos individualmente.

Com as tecnologias e ferramentas disponíveis na internet, o usuário pode facilmente aderir e escolher o que deseja receber de informação, publicidade, conteúdo e, principalmente músicas, conforme suas preferências.

O uso de músicas nos intervalos de programas transmitidos pelas rádios na web segue o modelo convencional de rádio, o que torna a rádio pela web mais uma rádio dentre as milhares existentes, modificando somente a plataforma de recepção da mesma, transmitida e recepcionada exclusivamente pela web.

O planejamento da playlist de músicas exibida por uma radioweb não tem diferença de um planejado por uma rádio normal, ambas constroem suas listas de forma a agradar seus ouvintes durante o intervalo entre os programas. A diferença pertinente à discussão deste artigo entre uma rádio comercial FM ou AM para uma rádio na web é que a primeira é baseada em uma relação comercial de lucro, a segunda baseia-se primordialmente em disseminação de informação, na tentativa de gerar conhecimento, não buscando lucros com impressões de banners ou mesmo com a veiculação de spots publicitários.

Partindo deste princípio, para fins de funcionalidade, ambas as rádios são iguais. Exibem músicas de autores brasileiros ou estrangeiros da mesma forma. A opção de não comercialização de horários, spots ou banners no site de uma radioweb é uma opção única e de exclusiva decisão de seus donos ou diretoria, tornando esta comercial ou não mesmo no ambiente da web.

Uma prática muito executada neste novo nicho de rádios na web é a duplicação de sinal. Rádios comerciais que anteriormente possuíam emissões somente via ondas eletromagnéticas, duplicaram seu sinal, emitindo a mesma programação comercial agora também pela web. Isso gera uma problemática pois o ouvinte locativo anteriormente conhecido pelas rádios, dá lugar ao ouvinte desterritorializado, não mais 
participe da massa locativa da cidade ou mesmo dentro da limitação territorial da emissão da radiofrequência. O ouvinte está pelo globo, ouvindo o conteúdo disponibilizado e também o spot publicitário ou comunicado de conteúdo locativo veiculado pela emissora. O que pode ocasionar uma certa revolta por estar recebendo um conteúdo que não colabora com a construção do imaginário desterritorializado muitas vezes desejado por este ouvinte "móvel". Por esta razão, defendo uma produção de um conteúdo diferenciado para uma rádio na web, mesmo esta sendo de uma empresa já emissora de conteúdo por intermédio da interface de uma rádio convencional.

\section{A expansão de rádios na web}

Como sabemos, diariamente surgem centenas de rádios na web que se juntam às milhares já existentes. O protocolo de streaming é muito fácil de ser utilizado e qualquer usuário com um acervo mediano de arquivos de áudio pode criar uma playlist e disponibilizar o acesso a sua máquina ou servidor, criando assim uma nova rádio. Não podemos esquecer que existem as grandes rádios na web patrocinadas pelas grandes empresas de comunicação e as pequenas rádios, que muitas vezes são de fóruns, comunidades, sites, blogs, flogs, ou provenientes de qualquer endereço com pequeno acesso diário. Observando o acesso às rádios pela ótica da cauda longa de Anderson (2006), temos muito mais acesso às pequenas rádios desconhecidas do grande público do que às grandes rádios do mainstream, essas mais facilmente localizáveis pelos ouvintes do que as pequenas rádios, que muitas vezes só possuem um IP, sem uma interface ou website propriamente construído ou mesmo divulgado.

Essas rádios, assim como todas as outras, executam músicas e áudios previamente selecionados pelos seus editores ou donos em sua playlist, mas assim como uma rádio de grande porte, também auxiliam na construção do imaginário do internauta ouvinte. 


\section{A reconfiguração da indústria cultural}

Segundo Castro (2007) existe uma linha bem definida sobre o que é pirataria e sobre o que são as novas práticas de consumo de música na web. A forma de consumo de produtos digitais assim como a própria cibercultura mesclada à nossa cultura contemporânea, abriu para nosso uso diário a ideia do compartilhamento de arquivos e de que todos os dados disponíveis na web podem ser trocados, enviados, recebidos e guardados. Isso já era uma prática feita pelo Naspter desde 1999, até a sua parada total (determinada pela justiça americana) em 2001.

O grande diferencial do Napster era de que o próprio servidor do Napster guardava e distribuía as músicas em formato MP3, o que caracterizava que o software realmente pirateava as músicas, distribuindo os arquivos para seus usuários.

Algum tempo depois, o software Napster modificou seu protocolo de conexão para utilizar o formato $\mathrm{P}^{\mathrm{P}} \mathrm{P}^{\mathrm{iv}}$, gerando a plataforma OpenNap, que depois foi usada como base para o i-Tunes que conhecemos, dando início a várias implementações para o comércio eletrônico de áudio e códigos para proteção de arquivos em MP3 por parte das gravadoras.

Com a mudança dos protocolos de troca e compartilhamento de arquivos para P2P, todo o conteúdo existente e disponibilizado na web, realmente não está na web. Está nos computadores pessoais de cada usuário da rede, não caracterizando uma posse e distribuição do conteúdo por intermédio de um único servidor, tornando a visão sobre "pirataria" um pouco mais difícil de ser atestada judicialmente com base em leis e punições para uma entidade ou empresa. Localizar de onde veio o arquivo, quem reproduziu e para quem reproduziu, torna-se uma tarefa praticamente impossível de ser levantada para fins punitivos, conforme a proposta de virtualização, globalização e desterritorialização de Levy (1996).

Existem hoje algumas modalidades de compartilhamento de P2P amplamente utilizadas, não só para músicas, mas para filmes, jogos, fotos e documentos, que são os agrupadores de links como o E-Mule e o Torrent ${ }^{v}$, estes também com variações de interfaces de download e gerenciamento. $\mathrm{O}$ arquivo baixado não está no E-Mule ou no Torrent, ele está na máquina de outras centenas ou milhares de usuários que vão lhe 
ceder pedaços até formarem o arquivo em seu computador pessoal. Nada é armazenado no servidor, somente o gerenciamento das conexões é feito, nada mais.

Mas onde podemos chegar com a junção da ideia das rádios na web, com os protocolos de $\mathrm{P} 2 \mathrm{P}$ para compartilhamento de arquivos e a disponibilidade de novas tecnologias para a mediação de toda esta informação?

O grande problema das milhares de rádios na web que não fazem parte do mainstream é o propósito de cada uma delas. Várias dessas rádios são feitas basicamente para comunicar, informar e compartilhar os desejos de seus donos, levando até o ouvinte desconhecido, as preferências do criador da playlist musical.

A estação de rádio, como forma particular de comunicação e linguagem, se apresenta como apenas um dos elementos constitutivos do perfil. Todavia, é complementar a todas as outras formas convergentes de participação cultural, como as práticas de social tagging (LAMERE; CELMA, 2007; AMARAL; AQUINO, 2008), de não-inclusão de determinadas músicas, como construção identitária, através do mecanismo de desligamento do rastreador, no caso do Last.fm (AMARAL, 2007), e de monitoramento, visualização e mapeamento dos dados musicais a partir do consumo dos usuários, como em alguns projetos que citaremos a seguir. (AMARAL, 2009)

Todo dia, temos centenas de rádios entrando no mundo virtual e tudo isso se dá de uma forma muita rápida, mas também muito fácil de ser entendida. Fidler identifica bem essa transposição do veículo rádio como parte da Mediamorfosis, sendo esta "a transformação dos meios de comunicação, como resultado da interação entre as necessidades percebidas, as pressões políticas e de competência, e das inovações sociais e tecnológicas" (1998, p.21).

O modo de como o imaginário e composto e construído pelas novas formas de comunicação e as novas tecnologias muda na mesma proporção em que, hoje, temos tipos de informações que nunca antes foram pensados em serem distribuídos em uma larga escala e para uma parte da população que não necessariamente acessava ou tinha acesso a este tipo de conteúdo. Com o surgimento dos prosumers (TOFFLER,1980) temos uma produção cultural muito mais abrangente e libertária por parte de que a disseminação das informações locais ou mesmo de opiniões individuais, atingem uma massa crítica muito maior, podendo assim transformar a rádio na web como um grande catalisador de informações específicas, transportando todas essas antigas rádios 
convencionais, agora na web, para a cauda longa de Anderson (2006) e a curva de Pareto, em um retorno para o mercado de nichos, segmentando cada vez mais a gama de ouvintes de cada uma das variadas rádios existente.

\section{Considerações finais}

Neste trabalho mostra-se como a construção do imaginário pode sofrer modificações com base no acesso às novas informações, anteriormente controladas pelas mídias manipuladoras e de massa, dando lugar às novas mídias proporcionadas pelas tecnologias disponíveis na interface da web e disponível para acesso pelos dispositivos móveis.

O ouvinte não mais se limita a informações locativas dos serviços, músicas ou informações disseminadas pelas rádios convencionais de sua cidade ou região. As informações dispostas em uma interface em rede, podendo ser acessadas de plataformas móveis, proporciona uma liberdade de expressão tanto pela parte do produtor e emissor da informação quanto pelo receptor, que agora, possui novas formas de interação com a mensagem ou veículo emissor, caracterizando uma maior possibilidade de adesão voluntária ao conteúdo em questão.

Indivíduos que nunca se imaginaram em contato com informações anteriormente segmentadas e restritas, estão recebendo informações sobre conteúdos que possivelmente alterarão seu modo de vida e comportamento, transformando-o não mais em um indivíduo pertencente a massa mas em um componente de vários possíveis mercados de nicho.

\section{Referências Bibliográficas}

ANDERSON, Cris. A cauda longa: do mercado de massa para o mercado de nicho. Rio de Janeiro: Elsevier, 2006.

AMARAL, Adriana. Plataformas de Música Online: Práticas de Comunicação e Consumo nos Perfis. In: XVIII Encontro Nacional da Compós, 2009, Belo Horizonte. Anais XVIII Compós. PUCMG, 2009. v. 1. BIANCO, Nélia R. Del. e MOREIRA, Sônia V. (org). Rádio no Brasil: tendências e perspectivas. Rio de Janeiro: Ed UERJ, 1999, p. 15-16. 
CASTRO, Gisela. Música, juventude e tecnologia: novas práticas de consumo na cibercultura. Logos (UERJ. Impresso), v. 1, p. 58-69, 2007.

. "Não é propriamente um crime": considerações sobre pirataria e consumo de música digital. Comunicação, Mídia e Consumo (São Paulo), v. 4, p. 73-88, 2007.

Computer Science at Columbia University. Session Initiation Protocol (SIP). Disponível em: http://www.cs.columbia.edu/sip . Acesso em: 20 setembro 2009.

FERRARETTO, Luiz Artur. Rádio: O veículo, a história e a técnica. Porto Alegre: Editora Sagra Luzzatto, 2000.

FIDLER, R. Mediamorfosis - comprender los nuevos medios. Buenos Aires, Granica, $1^{\mathrm{a}}$ edição, 1997.

HILLIS, Ken. Sensações Digitais: Espaço, identidade e corporificação na realidade virtual. São Leopoldo: Editora Unisinos, 1999.

JENKINS, Henry. Cultura da Convergência. São Paulo: Aleph, 2008.

JOHNSON, Steven. Cultura da Interface, Rio de Janeiro: Jorge Zahar Ed., 2001.

KEEN, Andrew. O Culto Do Amador: Como Blogs, Myspace, Youtube e a Pirataria Digital estão Destruindo Nossa Economia, Cultura e Valores, Rio de Janeiro: Jorge Zahar Ed., 2009.

LEMOS, Andre. Cibercultura e Mobilidade: a Era da Conexão disponível em http://www.razonypalabra.org.mx/anteriores/n41/alemos.html ano 2004. acesso em 30 novembro 2009.

2002. . Cibercultura. Tecnologia e Vida Social na Cultura Contemporânea. Porto Alegre: Sulina,

LÉVY, Pierre. O que é o Virtual. São Paulo: Ed. 34, 1996.

MORAN, José Manuel. Revista Ciência da Informação, Vol 26, n.2, maio-agosto 1997, pág. 146-153 Online. Disponível em <http://www.eca.usp.br/prof/moran/internet.htm> Acessado em 21 setembro 2009.

SILVA, Juremir Machado da. As Tecnologias do Imaginário. Porto Alegre: Sulina, 2003.

TOFFLER, Alvin. A terceira onda: a morte do industrialismo e o nascimento de uma nova civilização. 28.ed. Rio de Janeiro: Editora Record, 2005 


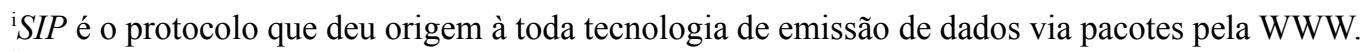

iiStreaming e podcast são tecnologias de emissão de dados multimídia em tempo real, onde o receptor não armazena os dados recebidos em sua máquina. Amplamente utilizada hoje por todos os sites transmissores de áudio e/ou vídeo.

iiiTermo utilizado para filtragem de informações a serem publicadas ou não.

iv 2P: Peer to Peer. Caracteriza uma transferência de arquivo ponto a ponto, usuário para usuário.

vSoftwares que trabalham com agrupamento de links de arquivos de todos os gêneros para download, comumente usados para download de filmes, jogos e músicas. http://www.emule.com ; http://www.bittorrent.com

Este artigo e todo o conteúdo da Estudos em Jornalismo e Mídia estão disponíveis em http://www.periodicos.ufsc.br/index.php/jornalismo/index

Estudos em Jornalismo e Mídia está sob a Licença Creative Commons. 